\title{
Position-define somatotype of Northern Mexican rugby players
}

\author{
Francisco Figueroa-Cavero*, Arturo Rodríguez-Ochoa, Agustín J. Alanís-Flores, \\ Yonny C. Carranza-Cervantes, Iliana E. Quintero-Raygoza and Oscar Salas-Fraire
}

Department of Sports Medicine and Rehabilitation, "Dr. José Eleuterio González" University Hospital, Autonomous University of Nuevo Leon, Monterrey, Nuevo Leon, Mexico

\begin{abstract}
Objective: This study intended to obtain the average somatotype for each rugby position in all active players from the state of Nuevo León, Mexico. This was a state of the art study of Mexican rugby players, having no record of previous research, and to make talent scouting and the development of performance analysis easier. Materials and methods: All of the registered and active rugby players from Nuevo León were measured through anthropometry with the method described by Heath-Carter, obtaining the necessary data to determine the somatotype. Body mass, skinfold sum, and height were quantified by direct methods, and body fat mass percentage was quantified by indirect methods. Results: $A$ total of 56 rugby players took part in the study, with an age of $21.7 \pm 4.7$ years. The average somatotype of the whole study group was 3.9 - 6.1 - 1.1, corresponding to endomorphy, mesomorphy, and ectomorphy, respectively, and matching with a mesomorphic and endomorphic profile except for one single subgroup, which matched with a mesomorphic and ectomorphic profile. Conclusion: There was not an evident difference between the somatotypes obtained for every subgroup, which were compared with similar studies made in rugby playing countries. The difference was more evident between position somatotypes. These variations between positions reflect the higher level of athletic specialization required for performance. The lack of variation between rugby position somatotypes reflects the low athletic level of Northeastern Mexican rugby. It is necessary for future research to enlarge the study and get an adequate sample size of the average Mexican rugby position somatotype.
\end{abstract}

Key words: Rugby. Somatotype. Anthropometry.

\section{Introduction}

Body size and composition are key factors in an athlete's performance in any sports discipline. They are useful outside as much as inside the field since they can be used as parameters for the selection and recruitment of athletes who meet certain criteria to carry out a specific role within the sport they practice. Moreover, it is important to conduct physical monitoring of a player to know with certainty that he/she is within the physical standards required for the moment of activity in which they are.

Somatotype is defined as the assessment of current human body type and composition, which is expressed in a series of three numbers that represent endomorphy, mesomorphy, and ectomorphy, respectively, and always in the same order ${ }^{1}$.

Endomorphy refers to relative body fatness, while mesomorphy is linked to musculoskeletal robustness;

\section{Correspondence:}

${ }^{*}$ Francisco Figueroa-Cavero

E-mail: pacofiguec@msn.com
Available online: 09-08-2019

Date of acceptance: 20-05-2019

DOI: 10.24875/RMU. 19000078
Medicina Universitaria. 2019;21(2):51-56 www.medicinauniversitaria.org CC BY-NC-ND license (http://creativecommons.org/licenses/by-nc-nd/4.0/). 
finally, ectomorphy evaluates the relative linearity or slenderness of the human body. This group of three values brings the possibility of cataloging the individual in a somatotype; there are 13 categories depending on the dominant values obtained from endomorphy, mesomorphy, and ectomorphy'.

Rugby is a team sport which is quite popular around the world, originating in England in the $18^{\text {th }}$ century as a derivative of football. With a considerable diffusion in English speaking countries such as Australia and New Zealand, Polynesian islands such as Fiji and Samoa, and in Latin American countries like Argentina, and in recent years, Mexico. The Rugby Union became professional in $1995^{2}$, after that, there has been a growing interest in the scientific study of the sport.

Rugby is a contact sport, where two teams formed by 15 players each have the purpose of obtaining possession of the ball to score points, either by placing the ball in the scoring zone or making the ball go through the posts of the opposing team. Each of the 15 players on the team has a specific position, highlighted with numbers from 1 to 15: (1) loose head prop, (2) hooker, (3) tight head prop, (4) lock and second row, (5) second row, (6) blind-side flanker, (7) open-side flanker, (8) number 8, (9) scrum half, (10) fly half, (11) left wing, (12) inside center, (13) outside center, (14) right wing, and (15) fullback ${ }^{3}$. Forwards are numbered from 1 to 8 and their main function is to win the ball during scrums in the game. These are the heavier and stronger players on the team since their functions require greater contact with the adversary.

The backs are formed by the positions 9-15 and their main function is to move the ball through the field. They are players with physical attributes focused on speed and explosiveness 4 .

Being a high physical contact sport, in recent years, the player selection process has evolved greatly, as has the focus of training aimed at obtaining anthropometric profiles that reach optimal performance in each of the 15 positions on a rugby team.

Globally, it is characteristic to appreciate different styles of play depending on the region where the sport is practiced. By tradition, it is said that countries in the Southern Hemisphere have a more aggressive and greater contact game, while countries in the Northern Hemisphere have a greater tendency toward dynamism and speed. A good part of these perceptions is due to the body types of the players in each region of the world. For example, in New Zealand, players of Maori heritage are much more valued by clubs since their body type and strength stand out above those players with an English heritage from the early stages.

By the year 2016, there were a total of 5464 players registered in the Mexican Federation of Rugby (FMRU by its Spanish acronym), from which 4117 were men and 1347 were women ${ }^{5}$.

Despite these numbers, Mexico does not appear at the highest level of competition in rugby, currently being at \#55 in the World Rugby ranking ${ }^{6}$. This is because, to a greater extent, the practice of the sport in the country is only at an amateur level, and the average age to start the sport is over 20 years. These factors affect the performance of the national teams, having players who do not have the physical requirements or the experience that the game demands at an international level. Knowing the somatotype of Mexican rugby players for each position would give us an idea of the projection and positioning that a Mexican player has compared to the international standard.

Tendencies toward professionalism and an increase in the playing level of rugby in the past decades have resulted in changes in the physical state of players worldwide, thus opening the way for the need to find standards in the protocols of physical measurement and monitoring. ${ }^{4}$ Unlike other sports such as football, volleyball, or basketball, where the anthropometric profiles among players are homogeneous, in rugby, variations in physical profiles for each of the positions are diverse, making each of them unique. This factor makes rugby an atypical sport when compared to other team sports ${ }^{7}$.

During the past three decades, a significant tendency of change in the body weight numbers of rugby players has been observed ${ }^{8}$. However, even though the increase has been proportional at inferior levels of competition, it is notoriously superior at a professional level. ${ }^{4}$ In rugby, an increase in body weight has a direct correlation with the total strength exerted at the scrum, which is one of the static formations of a dispute of possession where forwards are involved, and it is an important factor in the general development of a team ${ }^{8}$.

The fact that the forwards have a higher body weight than the backs is well-accepted; nevertheless, a reduction in the difference between these two types of players has been observed as the level of competition decreases ${ }^{9}$.

Similar to the trends observed with body weight, it has been observed that the higher the level of competition, the greater the height of the players. Specifically, there are positions that are predisposed to be covered by players of great height, such as the locks within the forwards and the centers in the backs. Such positions involve having the greatest height gain possible since 
they are in charge of playing the ball in the line-outs (kick-off), where it is essential to obtain the maximum reach in the formation?.

Studies have shown that the higher the level of competition, the lower the percentage of body fat. It has also been described that the difference between forwards and backs is lower in higher levels of competition; this possibly due to the higher demand and intensity of the training and diet involved. Just as a higher percentage of fat can be useful in contact situations as a shock absorber in the hit in the case of forwards, it can be counterproductive in situations where it is necessary to have greater speed and explosiveness, as is the case for the backs ${ }^{4}$.

\section{Materials and methods}

Under the structure of a population study, not experimental, descriptive, and cross-sectional, the sample was taken at convenience, considering all the rugby players of the Mexican state of Nuevo Leon active and registered at the Mexican Rugby Federation (FMRU) during the 2017-2018 season. They were considered as inclusion criteria that were active players registered in the FMRU, as well as active in clubs of higher category of the national tournament of the FMRU. As criteria of exclusion, it was taken that the player did not want to participate in the study, practice another sport at amateur level besides rugby, the anthropometric data sheet was incomplete and had not practiced rugby during the past year.

A search was made of players in clubs and rugby teams in the state of Nuevo León that met the inclusion criteria of the study. The procedure to be carried out was explained in person, verbally, and in full detail. A legend was placed on the data sheet of each individual that dictated: "I, the undersigned (name of the subject), give my consent to the responsible physician for the use of the data collected for research purposes" followed by his signature to show consent. Subgroups were made according to the game positions in rugby, being as follows: (1) first row, (2) second row, (3) third row (4) scrum-half, (5) fly-half, (6) center, and (7) Wing.

In certain work subgroups, more than one position was included for sharing physical profiles and functions within the field (e.g. the "wing" subgroup, which included the two wing players and the fullback, being players characterized by running and kicking long distances. The same with the "third row" subgroup, which included the two flankers and the number 8 , considering them as strong and fast players in charge of carrying out the most significant number of balls and tackles. On the other hand, there were subgroups that shared positions when dealing with pairs of players in the field (e.g., the "second row" subgroup and the "center" subgroup). These are strong and fast players in charge of carrying out the most significant number of balls and tackles; on the other hand, there were subgroups that shared positions when dealing with pairs of players in the field (e.g., the "second row" subgroup and the "center" subgroup). The measurements were taken in the morning, after fasting, and before doing any type of physical activity. Through direct questioning, the personal information of each player's data sheet was completed, and measurements were made corresponding to the restricted anthropometric profiles described by Heath-Carter $^{1}$ and in adherence to the guidelines established by the International Society for the Advancement of Kinanthropometry (ISAK). All measurements were made by a level 1 anthropometrist certified by ISAK. The variables collected were body mass, body size, the biepicondylar diameters of the humerus and femur, relaxed arm circumferences, contracted arm, waist, hip, and calf, as well as the skinfolds of the biceps, triceps, subscapular, iliocristale, supraspinal, anterior thigh, and medial calf muscles. As working material, a floor scale (Beurer ${ }^{\circledR}$ BG17, Ulm, Germany), a graduated metal strip (Lufkin ${ }^{\circledR}$ W606PM, Maryland, USA), a plicometer (Slim Guide, Plymouth, Michigan, USA), and a small caliber anthropometer (Cescorf ${ }^{\circledR}$ Innovare, Brazil) were used.

The equations method by Heath-Carter was used to obtain the somatotype and Durnin-Womersley formula ${ }^{10}$ to obtain the body fat percentage. After the data were downloaded into the computer, descriptive statistics (Microsoft $^{\circledR}$ Excel 2013, USA) were obtained, obtaining measures of central tendency and dispersion in each of the subgroups. The present work was evaluated and approved by the Research Ethics Committee of the "Dr. José Eleuterio González" University Hospital with the code MD17-00005.

\section{Results}

A total population of 56 individuals were obtained, of which $100 \%$ were male. About $96 \%$ (54/56) of the subjects were born in Mexico and 2\% (2/56) were born in Argentina. About $100 \%$ of the studied population had a Mexican nationality. From the total of the subjects within the study group, an average age of $21.7 \pm$ 4.7 years was obtained, with a sports experience of 3.4 \pm 3.5 years, a body height of $174.8 \pm 6.4 \mathrm{~cm}$, a body mass of $86.3 \pm 17.4 \mathrm{~kg}$, a body fat percentage of 21.3 $\pm 4.1 \%$, and a body mass index of $28.1 \pm 5.2$. The sum 
Table 1. Concentrated descriptive anthropometric data obtained and ordered by position, along with their respective standard deviations. Monterrey, Mexico, 2017

\begin{tabular}{|c|c|c|c|c|c|c|c|c|}
\hline & $\begin{array}{c}\text { First row } \\
(n=13)\end{array}$ & $\begin{array}{l}\text { Second row } \\
\qquad(n=5)\end{array}$ & $\begin{array}{l}\text { Third row } \\
(\mathbf{n}=11)\end{array}$ & $\begin{array}{l}\text { Scrum-half } \\
\qquad(n=4)\end{array}$ & $\begin{array}{l}\text { Fly-half } \\
(n=4)\end{array}$ & $\begin{array}{l}\text { Center } \\
(\mathrm{n}=7)\end{array}$ & $\begin{array}{l}\text { Wing } \\
(n=12)\end{array}$ & $\begin{array}{c}\text { Total } \\
(n=56)\end{array}$ \\
\hline $\begin{array}{l}\text { Basics } \\
\text { Age (years) } \\
\text { Experience (years) } \\
\text { Height (cm) } \\
\text { Body mass (kg) }\end{array}$ & $\begin{array}{c}23.5 \pm 6.2 \\
4 \pm 3.5 \\
175.1 \pm 3.5 \\
105.7 \pm 17.2\end{array}$ & $\begin{array}{c}22.4 \pm 2.3 \\
2.8 \pm 1.64 \\
186.1 \pm 1.6 \\
99.3 \pm 7.7\end{array}$ & $\begin{array}{c}22.9 \pm 4.45 \\
4.27 \pm 4.26 \\
176.3 \pm 7.38 \\
91.41 \pm 6.87\end{array}$ & $\begin{array}{c}21.5 \pm 3.69 \\
4.37 \pm 1.49 \\
168.06 \pm 5.25 \\
71.31 \pm 7.53\end{array}$ & $\begin{array}{c}22 \pm 3.65 \\
3 \pm 3.36 \\
173.02 \pm 2.68 \\
75.22 \pm 5.02\end{array}$ & $\begin{array}{c}21 \pm 6 \\
2.28 \pm 1.49 \\
170.51 \pm 3.52 \\
75.72 \pm 5.89\end{array}$ & $\begin{array}{l} \\
2.83 \pm 4.82 \\
174.13 \pm 5.41 \\
90.19 \pm 7.4\end{array}$ & $\begin{array}{c}21.75 \pm 4.73 \\
3.43 \pm 3.53 \\
174.89 \pm 6.40 \\
86.36 \pm 17.49\end{array}$ \\
\hline $\begin{array}{l}\text { Diameters }(\mathrm{cm}) \\
\text { Humerus } \\
\text { Femur }\end{array}$ & $\begin{array}{l}7.29 \pm 0.36 \\
10.4 \pm 0.70\end{array}$ & $\begin{array}{c}7.57 \pm 0.14 \\
10.01 \pm 0.15\end{array}$ & $\begin{array}{l}7.10 \pm 0.27 \\
9.96 \pm 0.35\end{array}$ & $\begin{array}{c}6.61 \pm 0.09 \\
9.5 \pm 0.15\end{array}$ & $\begin{array}{l}6.97 \pm 0.19 \\
9.71 \pm 0.26\end{array}$ & $\begin{array}{c}7.2 \pm 0.4 \\
9.92 \pm 0.34\end{array}$ & \begin{tabular}{l|l} 
& \\
$8.91 \pm 0.33$ \\
$9.42 \pm 0.42$
\end{tabular} & $\begin{array}{l}7.11 \pm 0.38 \\
9.91 \pm 0.58\end{array}$ \\
\hline $\begin{array}{l}\text { Circumferences }(\mathrm{cm}) \\
\text { Relaxed arm } \\
\text { Flexed arm } \\
\text { Waist } \\
\text { Hip } \\
\text { Calf }\end{array}$ & $\begin{array}{c}35.49 \pm 3.90 \\
38.21 \pm 2.69 \\
99.06 \pm 12.5 \\
110.8 \pm 7.71 \\
41.64 \pm 4.2\end{array}$ & $\begin{array}{c}35.09 \pm 3.20 \\
39.22 \pm 2.92 \\
90.57 \pm 5.62 \\
105.06 \pm 3.79 \\
39.74 \pm 1.49\end{array}$ & $\begin{array}{l}33.81 \pm 2.23 \\
36.72 \pm 2.56 \\
87.57 \pm 6.55 \\
101.2 \pm 3.63 \\
38.95 \pm 1.36\end{array}$ & $\begin{array}{l}29.13 \pm 2.21 \\
32.27 \pm 2.38 \\
76.71 \pm 6.01 \\
92.75 \pm 6.46 \\
35.02 \pm 0.47\end{array}$ & $\begin{array}{c}31.37 \pm 1.89 \\
34.45 \pm 1.21 \\
78.37 \pm 5.56 \\
94.31 \pm 3.94 \\
36.4 \pm 1.70\end{array}$ & $\begin{array}{c}31.41 \pm 2.29 \\
34.84 \pm 2.69 \\
82.01 \pm 4.34 \\
97 \pm 3.08 \\
37.59 \pm 2.25\end{array}$ & $\begin{array}{l}28.24 \pm 2.55 \\
31.91 \pm 1.92 \\
73.81 \pm 7.06 \\
92.16 \pm 4.86 \\
36.1 \pm 1.79\end{array}$ & $\begin{array}{c}32.31 \pm 3.96 \\
35.54 \pm 3.54 \\
85.43 \pm 12.21 \\
100.22 \pm 8.79 \\
38.4 \pm 3.31\end{array}$ \\
\hline $\begin{array}{l}\text { Folds (mm) } \\
\text { Biceps } \\
\text { Triceps } \\
\text { Subscapular } \\
\text { Iliac crest } \\
\text { Supraspinal } \\
\text { Abdominal } \\
\text { Anterior thigh } \\
\text { Medial calf }\end{array}$ & $\begin{array}{c}9.17 \pm 3.59 \\
15.9 \pm 5.9 \\
21.82 \pm 5.41 \\
31.17 \pm 7.05 \\
23 \pm 10.8 \\
32.69 \pm 7.86 \\
19.86 \pm 9.63 \\
16.96 \pm 7.87\end{array}$ & $\begin{array}{c}6.45 \pm 1.89 \\
10.4 \pm 2.59 \\
17.35 \pm 4.91 \\
31.65 \pm 6.9 \\
15.3 \pm 5.01 \\
25.1 \pm 7.71 \\
13.2 \pm 2.29 \\
11.05 \pm 3.13\end{array}$ & $\begin{array}{c}5.47 \pm 2.17 \\
10.63 \pm 2.87 \\
16.4 \pm 5.04 \\
22.47 \pm 4.97 \\
13.54 \pm 5.24 \\
22.81 \pm 9.73 \\
14.05 \pm 5.08 \\
11.29 \pm 3.24\end{array}$ & $\begin{array}{c}4.93 \pm 1.05 \\
8.87 \pm 3.25 \\
12.68 \pm 3.29 \\
19.62 \pm 4.29 \\
9 \pm 1.98 \\
16.43 \pm 3.88 \\
13.81 \pm 1.81 \\
11 \pm 2.22\end{array}$ & $\begin{array}{c}5.62 \pm 1.88 \\
11.18 \pm 2.41 \\
12.56 \pm 3 \\
25.5 \pm 8.71 \\
11.75 \pm 3.22 \\
25.18 \pm 10.77 \\
15.12 \pm 2.85 \\
11.25 \pm 1.69\end{array}$ & $\begin{array}{c}5.85 \pm 2.16 \\
10.92 \pm 4.16 \\
13.1 \pm 4.54 \\
20.21 \pm 4.92 \\
11.1 \pm 5.01 \\
19.85 \pm 8.15 \\
14.96 \pm 7.7 \\
9.6 \pm 5.7\end{array}$ & $\begin{array}{l} \\
4.97 \pm 1.29 \\
9.77 \pm 2.53 \\
10.43 \pm 3.63 \\
18.72 \pm 5.96 \\
9.95 \pm 4.69 \\
78.04 \pm 8.59 \\
12.81 \pm 4.57 \\
8.6 \pm 4.06\end{array}$ & $\begin{array}{c}6.33 \pm 2.81 \\
11.6 \pm 4.5 \\
15.51 \pm 6.08 \\
24.24 \pm 7.93 \\
14.37 \pm 8.22 \\
23.63 \pm 10 \\
15.23 \pm 6.73 \\
11.77 \pm 5.8\end{array}$ \\
\hline $\begin{array}{l}\text { Somatotype } \\
\text { Endomorphic } \\
\text { Mesomorphic } \\
\text { Ectomorphic }\end{array}$ & $\begin{array}{c}5.66 \pm 1.24 \\
7.40 \pm 1.44 \\
0.2 \pm 0.24\end{array}$ & $\begin{array}{c}3.96 \pm 1.16 \\
6.06 \pm 0.58 \\
1.04 \pm 0.5\end{array}$ & $\begin{array}{l}3.96 \pm 1.16 \\
6.28 \pm 1.05 \\
0.57 \pm 0.46\end{array}$ & $\begin{array}{l}3.15 \pm 0.47 \\
5.22 \pm 0.66 \\
1.25 \pm 0.34\end{array}$ & $\begin{array}{c}3.57 \pm 0.7 \\
5.6 \pm 0.69 \\
1.57 \pm 1.01\end{array}$ & $\begin{array}{c}3.5 \pm 1.31 \\
6.55 \pm 1.28 \\
1.21 \pm 1.06\end{array}$ & $\begin{array}{l}\frac{1}{2} .95 \pm 1.07 \\
\frac{2}{4} .75 \pm 1.12 \\
\frac{2}{9} .45 \pm 1.34\end{array}$ & $\begin{array}{c}3.99 \pm 1.46 \\
6.1 \pm 1.43 \\
1.13 \pm 1.13\end{array}$ \\
\hline $\begin{array}{l}\text { Indexes } \\
\text { BMI (kg.m²) } \\
\sum \text { folds }(\mathrm{mm}) \\
\text { Body fat }(\%)\end{array}$ & $\begin{array}{c}34.48 \pm 5.53 \\
170.59 \pm 46.55 \\
26.05 \pm 2.48\end{array}$ & $\begin{array}{c}28.67 \pm 2.06 \\
130.5 \pm 31.51 \\
22.76 \pm 2.89\end{array}$ & $\begin{array}{c}29.46 \pm 1.99 \\
116.71 \pm 30.21 \\
20.77 \pm 3.19\end{array}$ & $\begin{array}{c}25.05 \pm 1.49 \\
96.37 \pm 15.96 \\
18.52 \pm 2.49\end{array}$ & $\begin{array}{c}25.15 \pm 2.41 \\
118.18 \pm 30.69 \\
20.53 \pm 2.76\end{array}$ & $\begin{array}{c}26.11 \pm 2.85 \\
105.64 \pm 40.75 \\
19.98 \pm 3.23\end{array}$ & $\begin{array}{l}\mid \\
23.2 \pm 2.83 \\
93.33 \pm 30.79 \\
938.19 \pm 3.9\end{array}$ & $\begin{aligned} 28.17 & \pm 5.26 \\
122.71 & \pm 44.48 \\
21.34 & \pm 4.15\end{aligned}$ \\
\hline
\end{tabular}




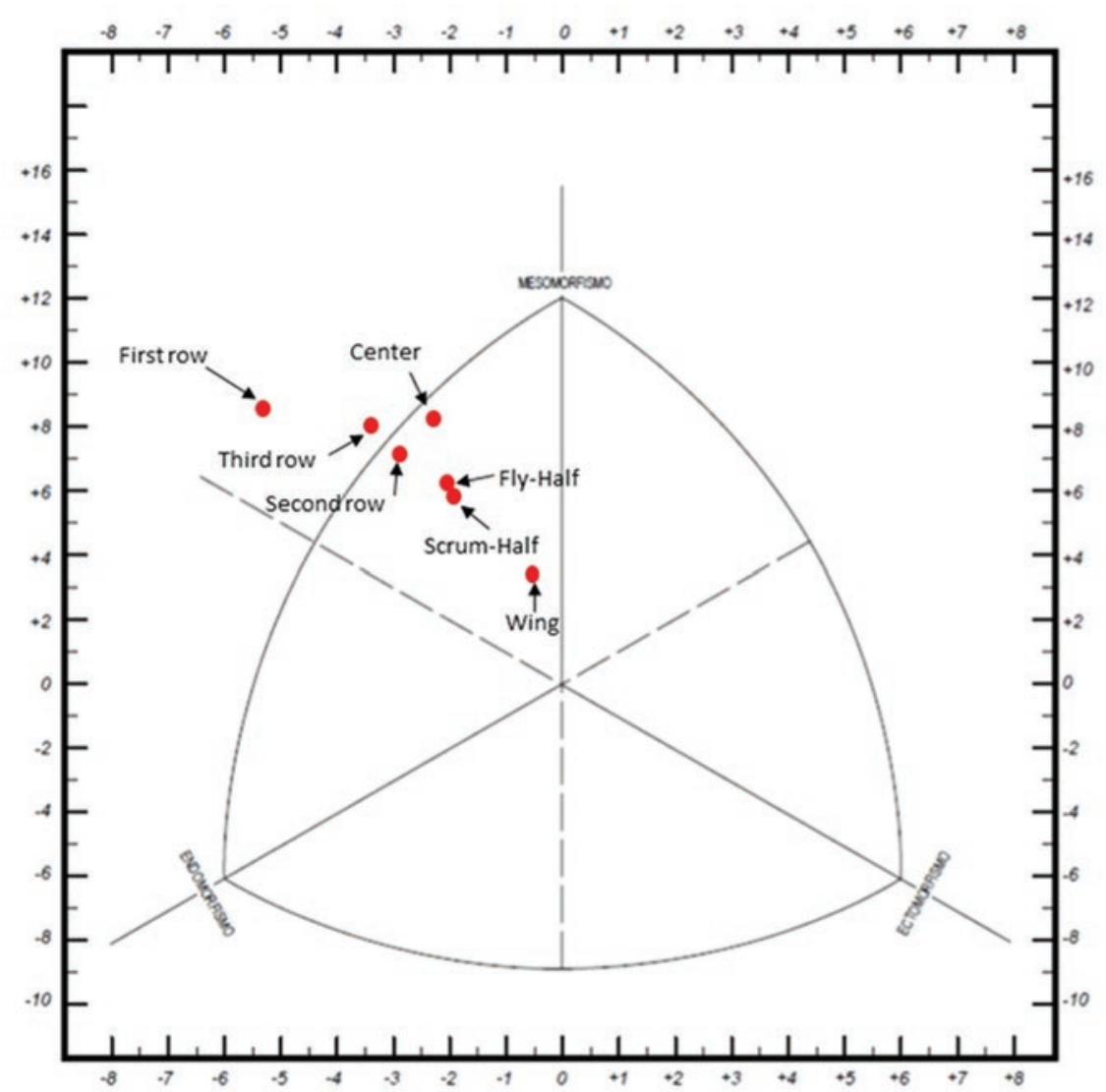

Figure 1. The average somatotypes obtained in each of the study subgroups. Monterrey, Mexico, 2017.

of their skin folds was calculated, which is considered a marker of greater objectivity on body fat ${ }^{4}$, obtaining an average of $122.7 \pm 44.48 \mathrm{~mm}$. The average somatotype obtained from the study group was $3.9-6.1$ - 1.1, corresponding to endomorphy, mesomorphy, and ectomorphy values, respectively, which are compatible with a mesomorphic and endomorphic somatotype.

Seven subgroups were formed, where more than one position was occasionally included in case of sharing common physical characteristics or being even positions. The results obtained for each subgroup are shown in table 1.

\section{Discussion}

As previously mentioned in the paper, the use of anthropometric measurements and obtaining body composition variables has been of great importance in modern sports for various purposes, as described by various authors ${ }^{11,12}$, among which is the prescription of nutritional and exercise plans, the search for specific talent, and the improvement of health, together with the increase of physical performance. It was not possible to find a difference in the average somatotype obtained from each of the positions since all of them presented a pattern of endomorphic mesomorph except the "Wing" subgroup, which presented a mesomorphic ectomorphic somatotype.

Although there was no difference in somatotype classification, certain changes and differences between subgroups can be seen when the mean endomorphy, mesomorphy, and ectomorphy scores in a somatocard are transposed (Fig. 1). Despite not being able to observe significant differences in the average somatotype, the results are similar to those of Holway and Garavaglia ${ }^{13}$ who determined the somatotype of Argentinian players by position and obtained a similar trend to that obtained with players in Mexico. Their average somatotype was also mesomorphic endomorphic, and they only had a subgroup with a balanced mesomorphic pattern (fullback). It has a certain coherence that the results obtained in the Argentinean population are similar to those obtained in the Mexican population since 
both the study groups share the characteristic of being a Latin population. However, it is important to take the historical and sportive background of Argentinian rugby into account since its players start the sport at a younger age and the intensity of the game is much more demanding compared to that of Mexican rugby. These factors must influence the tendency of reaching the requirements demanded by proper sports practice. Associating the above with the obtained results, it is observed that, in general, Mexican rugby players have little experience in the practice of the sport, which, added to not having an adequate somatotype, can predispose them to serious injuries in a more critical way than an experienced player. The results obtained in this study provide a general idea of the current situation of Mexican rugby. It is a sport that is in full development and in an important transition that involves the study and intervention of specific disciplines such as sports science and sports medicine to help provide a higher quality boost toward the international projection of the sport. It is important to catalog and have full knowledge of the types of players we have available, referring to their physical complexion and body composition.

Based on this precept, this study opens a research line in which eventually the average somatotype of the Mexican rugby player will be obtained, as a result it will be possible to establish a work basis to adapt the demands of the sport to the country's sportsmen. In parallel, we might work specifically with the establishment of training plans and sport initiation projects at an early age to achieve, in the long term, the standard physical profiles presented by the tier one rugby-playing countries.

\section{Conclusion}

The variability obtained within the anthropometric data in each of the work subgroups show the urgent need of defining the Mexican rugby player body composition and somatotype, in order to make possible to have the specific performance and development references. It is essential to have a wider population so that we can improve the statistical power of the results.

The projection reached with this investigation opens the pathway to keep the research line until acquiring the determination of the whole Mexican rugby players' somatotype.

\section{Acknowledgments}

We would like to thank the Monterrey Cumiyais Rugby Club, the University of Monterrey Troyanos Rugby team, and the Tigres Rugby team of the Universidad Autónoma de Nuevo León for their cooperation and participation in this study.

\section{Conflicts of interest}

The authors have no conflicts of interest to declare.

\section{Financing}

This study was financed by the Universidad Autonoma de Nuevo Leon, Department of Sports Medicine and Rehabilitation of the "Dr. José Eleuterio González" University Hospital.

\section{Ethical disclosures}

Protection of human and animal subjects. The authors declare that no experiments were performed on humans or animals for this study.

Confidentiality of data. The authors declare that they have followed the protocols of their work center on the publication of patient data.

Right to privacy and informed consent. The authors have obtained the written informed consent of the patients or subjects mentioned in the article. The corresponding author is in possession of this document.

\section{References}

1. Carter JE. The Heath-Carter Anthropometric Somatotype. Somatotype Instruction Manual. San Diego, CA: San Diego State University; 2002. p. 1-26.

2. Nicholas CW. Anthropometric and physiological characteristics of rugby union football players. Sports Med. 1997:23:375-96.

3. World Rugby. Laws of the Game Incorporating the Playing Charter; 2016. p. 113-4. Available from: http://www.laws.worldrugby.org/downloads/ World Rugby Laws 2016 EN.pdf.

4. Duthie G, Pyne D, Hooper S. Applied physiology and game analysis of rugby union. Sports Med. 2003;33:973-91.

5. Federación Mexicana de Rugby. Censo de Jugadores 2015-2016. Mexicano: Observaciones no Publicadas.

6. World Rugby (TM) Rankings; 2016. Available from: http://www.worldrugby.org/rankings/mru.

7. Quarrie KL, Handcock P, Toomey MJ, Waller AE. The New Zealand rugby injury and performance project. IV. Anthropometric and physical performance comparisons between positional categories of senior a rugby players. Br J Sports Med. 1996;30:53-6.

8. Olds $T$. The evolution of physique in male rugby union players in the twentieth century. J Sports Sci. 2001;19:253-62.

9. Quarrie KL, Handcock P, Waller AE, Chalmers DJ, Toomey MJ, Wilson $\mathrm{BD}$, et al. The new zealand rugby injury and performance project. III. Anthropometric and physical performance characteristics of players. Br J Sports Med. 1995;29:263-70.

10. Durnin JV, Womersley J. Body fat assessed from total body density and its estimation from skinfold thickness: measurements on 481 men and women aged from 16 to 72 years. Br J Nutr. 1974;32:77-97.

11. Ackland TR, Elliott BC, Bloomfield J. Applied Anatomy and Biomechanics in Sport. $2^{\text {nd }}$ ed. Champaign, IL: Human Kinetics; 2009. p. 55.

12. Spamer EJ, De la Port Y. Anthropometric, physical, motor, and game-specific profiles of elite $U 16$ and $U 18$ yearold South African schoolboy rugby players. Kinesiology. 2006;38:176-84

13. Holway FE, Garavaglia R. Kinanthropometry of group I rugby players in buenos aires, argentina. J Sports Sci. 2009;27:1211-20. 